\title{
BOTULINUM TOXIN TYPE A IN THE TREATMENT OF LOWER-LIMB SPASTICITY IN CHILDREN WITH CEREBRAL PALSY
}

\author{
Carlos Henrique F. Camargo', Hélio A.G. Teive ${ }^{2}$, Marise Zonta ${ }^{3}$, Gilmar C. Silva ${ }^{3}$, Marcelo R. Oliveira', \\ Maurício M. Roriz', Ivar V. Brandi', Nilson Becker', Rosana Hermínia Scola ${ }^{2}$, Lineu César Werneck ${ }^{4}$
}

\begin{abstract}
We evaluated the safety and effectiveness of botulinum toxin A (BoNT/A) in the treatment of spasticity in 20 children with spastic diplegic cerebral palsy (CP). All the patients received injections in the gastrocnemius and soleus, and 15 received injections in the adductors. The total dose varied from 70 to $140 \mathrm{U}$ (99.75 $\pm 16.26 \mathrm{U})$, or $7.45 \pm 2.06 \mathrm{U} / \mathrm{kg}$ per patient. The treatment improved the patients' walking and gait pattern significantly. There was also a significant alteration in the heel-ground distance and increased motion of the ankle joint. These structural changes in the feet were sustained until the end of the follow-up, although the same was not observed for the functional parameters. Three patients complained of weakness in the lower limbs. In conclusion, BoNT/A is safe and effective when used in a single session of injections and produces a sustained structural modification of the lower limbs. However, functional changes are temporary and are only observed during the peak effect of the drug.
\end{abstract}

KEY WORDS: cerebral palsy, botulinum toxin, spasticity.

Toxina botulínica tipo A como tratamento para espasticidade de membros inferiores em crianças com paralisia cerebral

\begin{abstract}
Resumo - Para avaliação da segurança e eficácia do tratamento com toxina botulínica A (TB-A) na espasticidade na paralisia cerebral (PC), foram selecionadas 20 crianças com a forma diplegia espástica. Todos os pacientes receberam injeções nos gastrocnêmios e sóleos, 15 receberam doses nos adutores da coxa. A dose total variou de 70 a $140 \mathrm{Us}(99,75 \pm 16,26 \mathrm{U}), 7,45 \pm 2,06 \mathrm{U} / \mathrm{Kg}$ por paciente. O tratamento com a TB-A melhorou significativamente a deambulação e o padrão de marcha. Houve também significativa alteração da distância tornozelo-solo e aumento da amplitude de movimento da articulação do tornozelo. Essas mudanças estruturais dos pés se mantiveram até o final do acompanhamento. O mesmo não foi observado com parâmetros funcionais. Três pacientes apresentaram fraqueza em membros inferiores. Conclui-se que a TB-A, em uma única aplicação, é segura e eficaz. Há modificação sustentada da estrutura motora dos membros inferiores, porém mudanças funcionais são temporárias, durante o pico de ação do medicamento.
\end{abstract}

PALAVRAS-CHAVE: paralisia cerebral, espasticidade, toxina botulínica.

Cerebral palsy (CP) can be defined as a movement and posture disorder that appears at an early age, is secondary to a lesion or dysfunction of the central nervous system and is not caused by any known progressive or degenerative brain disease. The medical history, together with a neurological exam, allow the cause of the motor deficit to be identified as a brain abnormality and a diagnosis of CP to be made ${ }^{1}$. CP is a widespread problem and has a worldwide incidence of approximately 2 to 2.5 cases per 1,000 live-born infants. The condition is most common in premature children, who represent approximately $65 \%$ of all cases. The different types of CP have been well established and classified according to the degree of motor impairment in spastic, dyskinetic, ataxic, hypotonic and mixed $C P^{2}$. The most common form of CP is spastic diplegia, which manifests mainly in the lower limbs and has a well-established association with prematurity ${ }^{3,4}$.

Spasticity in children with CP is a serious problem that affects daily life activities and places obstacles in the path to achieving the rehabilitation goals. Stiffness, restricted movement, the development of contractures and a serious potential for joint complications are associated

Movement Disorders Unit, Neurology Service, Department of Clinical Medicine, Hospital de Clínicas, Universidade Federal do Paraná, Curitiba PR, Brazil: 'Neurologist; ${ }^{2}$ Associate Professor; ${ }^{3}$ Physiotherapist; ${ }^{4}$ Full Professor.

Received 11 April 2008, received in final form 3 October 2008. Accepted 17 November 2008.

Dr. Hélio A.G. Teive - Rua General Carneiro $181 / 12 \%$ andar-80060-900 Curitiba PR - Brasil.E-mail: hagteive@mps.com.br 
with muscles affected by spasticity ${ }^{5}$. Botulinum toxin A (BoNT/A), a practical neuromuscular blocking agent that causes a clinical reduction in spasticity in working muscles, appears to have a beneficial effect on the natural history of CP patients with equinus deformity.

The objective of the present study was to evaluate the safety and effectiveness of BoNT/A in the treatment of children with spastic diplegic cerebral palsy.

\section{METHOD}

Patient selection

Twenty patients with spastic diplegic $\mathrm{CP}$ who had been referred to the Botulinum Toxin Outpatient Unit in the Neurology Service, Hospital de Clínicas, Federal University of Paraná (HCUFPR), between May and November 2000 were selected.

The inclusion criteria were: (1) children from 2 to 16 years of age; (2) patients with dynamic deformities of the lower limbs due to static cerebral lesion with poor response to physiotherapy (dynamic deformities were considered to be those in which the limb could return to the neutral position with maximal or submaximal passive manipulation); (3) patients who were able to walk with or without assistance; and (4) patients taking part in rehabilitation programs.

The exclusion criteria were: (1) fixed deformity of a joint; (2) prior orthopedic surgery or the need for surgical treatment; (3) prior use of botulinum toxin; (4) myasthenia gravis or a disease of the neuromuscular junction; (5) use of aminoglycoside antibiotics; (6) physiotherapy discontinued; and (7) consent not given by those responsible for the patient.

\section{Assessment and clinical follow-up}

All the patients had the diagnosis of spastic diplegic CP confirmed by at least two neurologists following clinical examination and neuroimaging and laboratory tests. Each patient was then assessed by at least one physiotherapist before being included in the study.

The patients were assessed on admission and approximately 30,90 and 180 days after treatment had started. This assessment consisted of:

1 - Clinical neurological and physiotherapy assessment.

2 - Measurement of the degree of hip abduction, knee extension and ankle dorsiflexion. The ankle dorsiflexion angle with the knee at maximum extension and $90^{\circ}$ of flexion was measured using the goniometer. With the foot placed in the supine position, the ankle was kept in the neutral position to avoid calcaneus valgus or varus and dorsiflexed to the limit of movement. The fixed arm of the goniometer was kept parallel to the long axis of the fibula, and the mobile arm parallel to the long axis of the calcaneus.

3 - Ashworth Spasticity Scale. Assessment of the tonus of the triceps surae during passive dorsiflexion of the ankle with the knee and thigh flexed ${ }^{7}$.

4 - Physician Rating Scale (PRS). This scale allows six func- tional elements of gait to be assessed while the patient is walking barefoot for a distance of at least 15 steps. This scale grades the following functional elements: (1) gait pattern (0-2); (2) position of the ankle while walking (0-2); (3) elevation and curvature of the foot while walking (0-3); (4) position of the knee while walking (0-3); (5) degree of flexion and shortening of the lower limbs (0-3); and (6) gait speed (0-1). The total PRS score was the sum of the six components for each patient $(0-14,0=$ worst score and 14=best score $)^{8}$.

5 - Ambulation speed. A measurement of the time needed to cover a distance of 25 steps with or without assistance.

6 - Heel-ground distance. Measured with the patient in the orthostatic position with the knee at maximum extension.

7 - Spasticity scale for thigh adductors: 0 -normal muscle tonus; (1) increased tonus, thighs easily abducted up to $45^{\circ}$ by only one examiner; (2) thighs abducted up to $45^{\circ}$ by only one examiner with minor effort; (3) thighs abducted up to $45^{\circ}$ by only one examiner with moderate effort; (4) two examiners needed to abduct thighs up to $45^{\circ}$.

8 - Analysis of gait using video recordings.

All participants were required to continue physiotherapy throughout the study in the same institutions they had been having treatment in prior to the application of botulinum toxin. The staff at these centers were advised by the physiotherapists from the HC-UFPR to continue a program of at least three 1-hour sessions a week containing, as a minimum: (1) muscle stretching, especially for the Achilles tendon; (2) exercises to assist ankle dorsiflexion; (3) gait training going up and down steps; (4) training of those responsible for the child to ensure that certain exercises were repeated as part of the child's daily routine.

\section{Treatment}

The clinical treatment patients had been receiving prior to inclusion in the study was continued, and none of the patients were submitted to surgery during the study. All the patients received BoNT/A therapy (Botox ${ }^{\circledR}$, Allergan, Irvine, CA, USA).

The lyophilized preparation of the toxin ( 1 flask=100 $\mathrm{U}=5 \mathrm{ng}$ ) was stored at $-20^{\circ} \mathrm{C}$ and reconstituted with $1 \mathrm{~mL}$ of $0.9 \%$ saline solution at the time of injection. The $10 \mathrm{U}$ per $0.1 \mathrm{~mL}$ solution was administered in a $1 \mathrm{cc}(1 \mathrm{~mL})$ tuberculin syringe.

The number of points where the toxin was injected and the dose were adjusted for each muscle (Table 1). The maximum doses used for BoNT/A injections were: (a) $12 \mathrm{U} / \mathrm{kg}$ or $400 \mathrm{U}$ per session; (b) 3-6 U/kg per large muscle; (c) 1-2 U/kg per small muscle; and (d) $50 \mathrm{U}$ per injection point. ${ }^{7}$

The choice of muscle, site and amount of BoNT/A for each muscle were determined based on clinical evaluation with the aid of electromyography (Table 1). BoNT/A was applied using a Nihon-Kohden Neuropack II electromyograph. Monopolar, teflon-coated needle electrodes were used ( $37 \mathrm{~mm} \times 27 \mathrm{G}$ ), and the tuberculin syringe was coupled to a needle electrode. The appliance was calibrated with filters from $10 \mathrm{~Hz}$ to $5 \mathrm{kHz}$. A sensitivity of 100 microvolts $(\mu \mathrm{V}) /$ division was used and the analysis time 
Table 1. Pediatric doses of botulinum toxin A (Botox ${ }^{\circledR}$ Allergan) for lower-limb spasticity.

\begin{tabular}{|c|c|c|c|}
\hline & Muscle & Dose (U/kg) & Number of injection sites \\
\hline \multirow[t]{2}{*}{ Hip flexion } & Iliopsoas & $1-2$ & 2 \\
\hline & rectus femoris & $3-4$ & 2 \\
\hline \multirow[t]{3}{*}{ Knee flexion } & middle biceps femoris & $3-6$ & $3-4$ \\
\hline & lateral biceps femoris & $2-3$ & $1-2$ \\
\hline & gastrocnemius & $3-6$ & $2-4$ \\
\hline Thighs adducted & adductor longus and brevis & $3-6$ & $1-2$ \\
\hline Knee extended & quadriceps & $3-6$ & 4 \\
\hline \multirow[t]{6}{*}{ Equinovarus } & medial and lateral gastrocnemius & $3-6$ & $1-2$ \\
\hline & soleus & $2-3$ & $1-2$ \\
\hline & tibialis posterior & $1-2$ & 1 \\
\hline & tibialis anterior & $1-3$ & 1 \\
\hline & flexor digitorum brevis and flexor digitorum longus & $1-2$ & 1 \\
\hline & flexor hallucis longus & $1-2$ & 1 \\
\hline Hallux extended & extensor hallucis longus & $1-2$ & 1 \\
\hline
\end{tabular}

was 10 milliseconds/cm. After the muscle where the BoNT/A was to be injected had been chosen, the needle electrode was inserted at the site nearest to the motor point, and when the presence of motor unit action potentials (MUAPs) suggested that the needle was inserted in the muscle, the BoNT/A was injected.

Adverse effects, latency to start, peak and duration of action of the BoNT/A and interference in daily life were measured with a questionnaire.

\section{Statistical analysis}

The distribution pattern for all the data was tested (normal or non-normal). The statistical differences between the means of the groups were determined using two-tailed and single-tailed paired Student $t$ tests where indicated and the Wilcoxon test. The results are given as mean \pm SD (standard deviation). All the statistical analysis was performed with version 99 of the Statistica for Windows program. Differences were considered significant if $\mathrm{p}<0.05$.

\section{RESULTS}

All 20 children selected $[13$ males and 7 females aged between 2 and 11 years ( $4.73 \pm 2.18$ years) and weighing between 8 and $34 \mathrm{~kg}(12.72 \pm 5.87 \mathrm{~kg})]$ received BoNT/A injections at the beginning of the study. All had equinus in both feet and were given BoNT/A injections in the gastrocnemius and soleus muscles. There was no statistically significant difference between the severity of the deficit in the lower right limbs and that in the lower left limbs ( $p=0.827)$. Fifteen patients had difficulty abducting their thighs and therefore had BoNT/A injected in the thigh adductors.

The BoNT/A dose varied from 70 to 140 Us (99.75 \pm 16.26 $U$ ) and was $7.45 \pm 2.06 \mathrm{U} / \mathrm{kg}$ per patient. The parents or those responsible for the children reported that the medication started having an effect between the second and

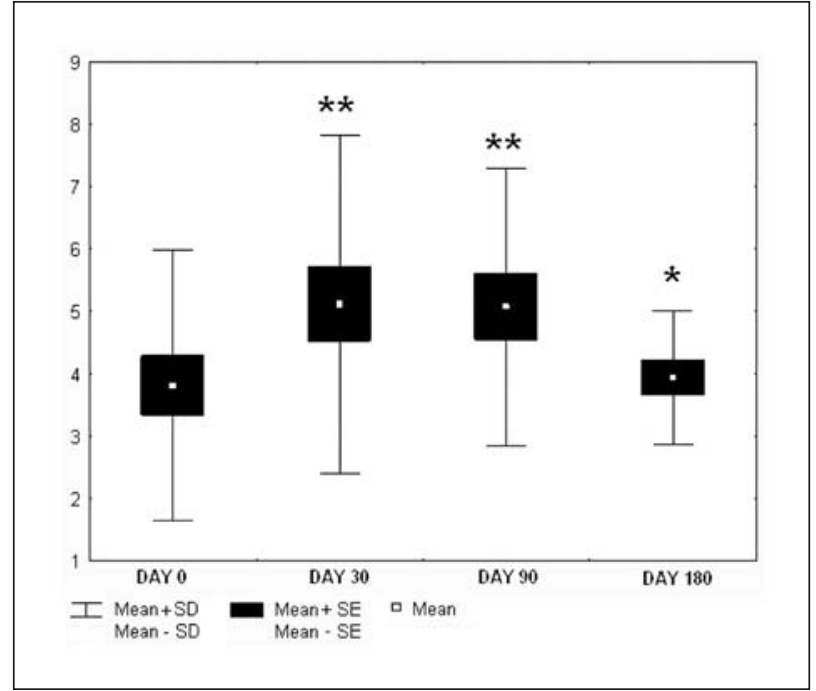

Fig 1. Response to treatment with botulinum toxin A on the Physician Rating Scale. ${ }^{* *} p<0.001$ in relation to day $0 ;{ }^{*} p<0.05$ in relation to day 30.

twentieth day after application (7.1 \pm 4.57 days). All the patients attended for follow-up assessment at 30 days postapplication, $85 \%$ attended for assessment at 90 days and $75 \%$ at 180 days.

Treatment with BoNT/A improved ambulation and equinus gait pattern significantly in children with spastic diplegia when these parameters were assessed using the PRS $(p<0.001)$. The treatment continued to have beneficial effects at the follow-up assessment 90 days post-treatment $(p<0.001)$. At the follow-up assessment 180 days post-treatment, however, parameters similar to those prior to treatment were observed (Fig 1). Only two children (10\%), who had severe functional impairment at the beginning of the study, failed to show any improvement on 


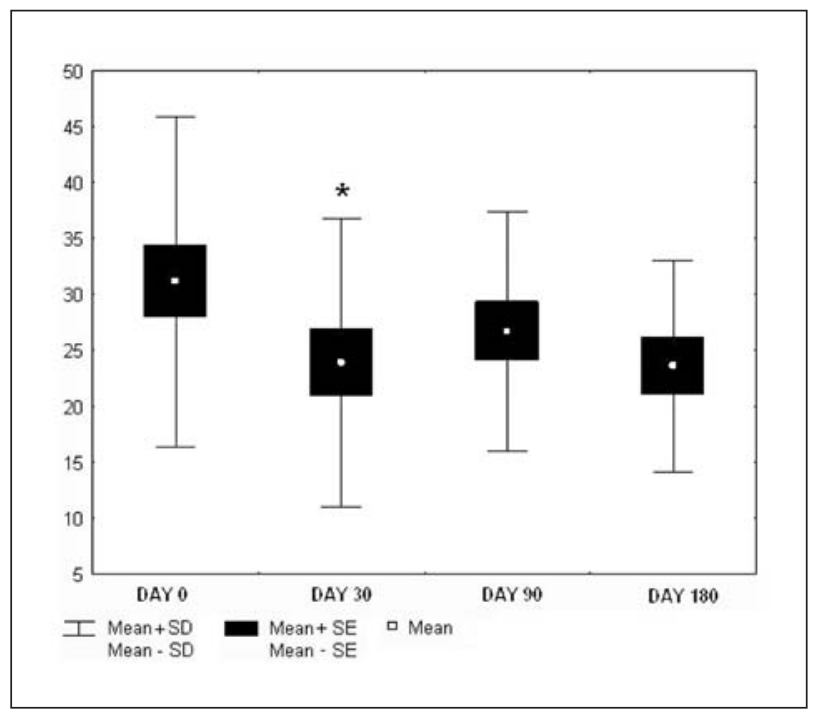

Fig 2. Response to treatment with botulinum toxin $A$ measured by gait speed (sec/25 steps). ${ }^{*} p<0.05$ in relation to day 0 .

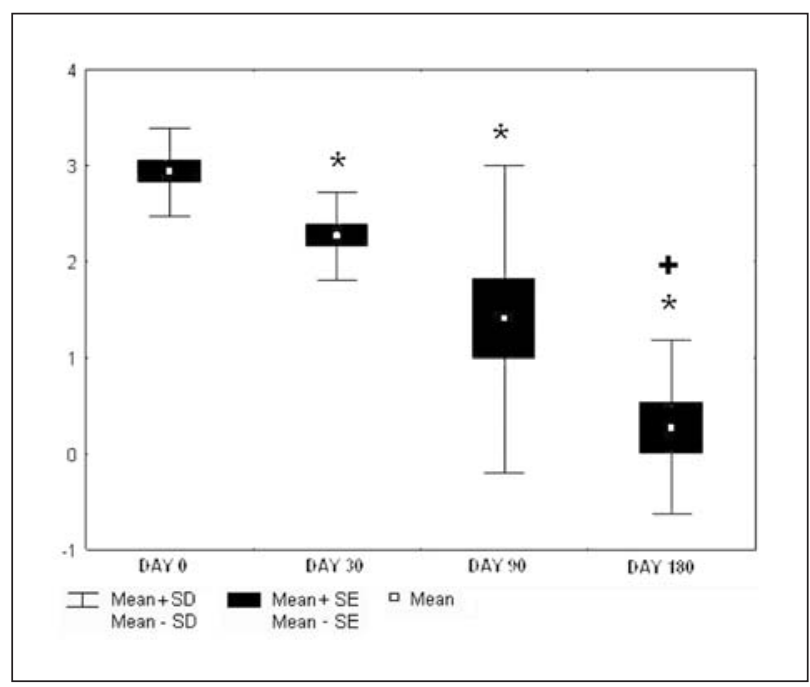

Fig 3. Response of spastic thigh adductor muscles to treatment with botulinum toxin $A .{ }^{*} p<0.05$ in relation to day $0 ;+p<0.05$ in relation to day 30 .

Table 2. Parameters to assess the effect of botulinum toxin A (Botox ${ }^{\circledR}$ Allergan) on the gastrocnemius and soleus muscles.

\begin{tabular}{|c|c|c|c|c|c|c|}
\hline & Day 0 & Day 30 & $\begin{array}{l}\mathrm{p} \text { in relation } \\
\text { to Day } 0\end{array}$ & Day 180 & $\begin{array}{l}\mathrm{P} \text { in relation } \\
\text { to Day } 0\end{array}$ & $\begin{array}{l}\mathrm{p} \text { in relation } \\
\text { to Day } 30\end{array}$ \\
\hline $\mathrm{R}$ heel-ground distance $(\mathrm{cm})$ & $1.92(1.54)$ & $1.17(1.47)$ & $p=0.041$ & $1.28(0.84)$ & $p=0.034$ & $p=0.43$ \\
\hline L heel-ground distance $(\mathrm{cm})$ & $2.22(1.72)$ & $1.35(1.75)$ & $p=0.042$ & $1.13(0.99)$ & $p=0.011$ & $p=0.183$ \\
\hline $\begin{array}{l}\mathrm{R} \text { ankle dorsiflexion angle } \\
\text { with the knee flexed (?) }\end{array}$ & $-24(21.31)$ & $-3.5(38.56)$ & $p=0.005$ & $8.33(31.03)$ & $p=0.001$ & $p=0.494$ \\
\hline $\begin{array}{l}\mathrm{L} \text { ankle dorsiflexion angle } \\
\text { with the knee flexed (?) }\end{array}$ & $-22.5(21.85)$ & $1(37.50)$ & $p=0.001$ & $12(31.89)$ & $p=0.0009$ & $p=0.926$ \\
\hline $\begin{array}{l}\mathrm{R} \text { ankle dorsiflexion angle with } \\
\text { the knee extended (?) }\end{array}$ & $-16(17.06)$ & $0.75(26.62)$ & $p=0.001$ & $8(21.36)$ & $p=0.004$ & $p=0.901$ \\
\hline $\begin{array}{l}\mathrm{L} \text { ankle dorsiflexion angle with } \\
\text { the knee extended (९) }\end{array}$ & $-14.5(15.12)$ & $-1.5(26.26)$ & $p=0.007$ & $5.33(23.02)$ & $p=0.013$ & $p=0.884$ \\
\hline Ashworth Spasticity Scale & $3(0.45)$ & $2.6(0.11)$ & $p=0.003$ & $2.55(0.21)$ & $p=0.029$ & $p=0.407$ \\
\hline
\end{tabular}

Values shown as averages and standard deviations. R, right, L, left, cm, centimeter; *Botox ${ }^{\circledR}$ Allergan.

the PRS scale at the +30 day follow-up assessment and did not attend for reassessment at +180 days.

Gait speed also changed significantly as a result of the use of BoNT/A ( $<<0.05)$. Nevertheless, this improvement was not sustained, as can be seen in the +90 and +180 day follow-up assessments (Fig 2). Three patients (15\%) were able to ambulate without any support in all the follow-up assessments. One patient who required support when walking at the first, second and third follow-up assessments, managed to ambulate without support at the +180 day follow-up assessment. The remaining 16 patients (80\%) were unable to ambulate without assistance at any of the assessments.

Assessment of triceps surae spasticity with the Ashworth scale showed that there was a significant response to BoNT/A ( $<<0.05)$, which was still in evidence at day $90(\mathrm{p}<0.05)$, but that the muscles had returned to their baseline values at day 180. The response of these muscles was also tested by measuring ankle dorsiflexion. When this method of assessment was used, both with the knee flexed or at maximum extension, there was a significant response to BoNT/A in both limbs, and this was sustained until the end of the study. The heel-ground distance, which is increased in equinus because of the spasticity of the triceps surae, also changed significantly following the application of BoNT/A, and the results were sustained until day 180 (Table 2).

The thigh adductor muscle group also responded significantly to the therapy, and the longer the time elapsed since the BoNT/A injection, the greater was the response (Fig 3).

Three patients were found to have weakness in the lower limbs after BoNT/A had been applied, and one report- 
ed having falls. These symptoms were mild and resolved in a few weeks without the need for medical intervention.

\section{DISCUSSION}

In this study we have shown that the use of intramuscular BoNT/A injections to treat children with CP (spastic diplegia) who have spastic thigh adductor muscles and equinus is both safe and effective.

Treatment with BoNT/A was very effective in correcting the position of the feet, as shown by the reduction in the heel-ground distance and by the increased range of motion of the ankle joint, confirming the findings of previous studies ${ }^{10-15}$. The increased dorsiflexion of the foot caused by the greater range of motion of the ankle joint was similar both with the knee extended and with the knee flexed. This occurred because of the role of all the muscles in the triceps surae complex - gastrocnemius and soleus - in producing equinus in our patients ${ }^{16}$. There was thus an effective response to BoNT/A in all these target muscles. The improved positioning of the feet was also confirmed by the reduction in spasticity in the triceps surae muscles measured on the Ashworth scale. Physiological explanations for this adjustment in the feet include not only weakening of the gastrocnemii and soleus but also the increase in length of the gastrocnemii muscle-tendon unit, the shortening of the antagonist muscles or a combination of these events. Any of these effects could be the direct result of chemical denervation caused by BoNT/A, and it is unlikely that they would occur spontaneously".

A clear improvement in the spasticity of the thigh adductor muscles was also observed after treatment with BoNT/A, corroborating the findings of other studies ${ }^{5}$. The positive effect on the thigh adductor muscles was progressive and was sustained throughout the follow-up period. We observed that the beneficial effects of BoNT/A in terms of spasticity of the triceps surae were still present six months after the application of the toxin. The effects of a single dose of BoNT/A lasted on average three to six months in other studies of children with CP. Although the duration and effect of BoNT/A reported in the literature varies, it is generally considered to be effective for at least three months".

All our patients took part in rehabilitation programs before and after the application of BoNT/A, preferably based on a neurophysiological method, using splints when necessary. The use of electrical stimulation and immobilization was not recommended ${ }^{14,16}$. We believe that the prolonged positive effect of BoNT/A - until the end of the study in some cases - is also related to the results of physiotherapy ${ }^{11,17}$. Thus, BoNT/A should not be considered a substitute for physiotherapy or orthoses, but rather an additional therapeutic strategy ${ }^{10,18}$. Better biomechanical alignment through muscular relaxation, such as improved range of motion of the ankle, allows the patient to adapt better to orthoses ${ }^{10,11}$. Furthermore, the muscular relaxation achieved following application of BoNT/A allows muscle-stretching exercises to be performed more easily and the child to learn to use and strengthen opposing muscles. For most children BoNT/A does not lead to a sustained increase in the length of the gastrocnemii but helps delay shortening of the muscles. Specific physiotherapeutic treatment and orthoses can help the small percentage of children in whom there is evidence of prolonged muscle stretching ${ }^{19}$. These are clear arguments for intensifying physiotherapy after the application of BoNT/A to achieve better results in the long term $6,0,1,1,20$.

The impact of BoNT/A in children is different from that in adults. Unlike adults, whose organisms are relatively static, children have two processes that are exclusive to childhood - growth and development - superimposed on the underlying spastic condition. Although the effects of BoNT/A are seen primarily in a reduction of hypertonia, the change in tonus can improve the child's balance, strength, motor control and fixed contractures ${ }^{21}$. As the child develops, the spastic muscles fail to grow as quickly as the neighboring structures, and dynamic structures are transformed into fixed contractures. Relaxation of spastic muscles allows these to stretch, encourages their growth and prevents contractures. These improvements lead to functional gain ${ }^{10}$.

It has been stressed recently that assessment of functional improvement is more important than assessment of the reduction in muscle tonus or the increase in the range of motion of the joint ${ }^{10,18}$. The physiological and mechanical effects of BoNT/A treatment are genuine and measurable in patients with spastic diplegia. However, these effects may not trigger a major change in function or change in the patient's or his/her parents' perception of function and thus not be recorded as a significant improvement in the patient's family and social life ${ }^{22}$.

Hesse et al. ${ }^{12}$ reported a noticeable improvement in equinus followed by a more erect gait posture after injection of BoNT/A in the gastrocnemius and ischiotibial muscles. However, there was no functional improvement according to the assessment tools used. Reddihough et al. ${ }^{23}$ observed discrete gait improvements after three months of follow-up, but failed to observe functional improvements after 3 or 6 months. Fazzi et al. ${ }^{13}$, on the other hand, observed a reduction in spasticity in muscles that had been treated and an increase in passive joint mobility. There was increase in the scores on scales and tests intended to assess function. These increases are reflected in the gait pattern (PRS), selective motor control in foot dorsiflexion, and the acquisition of new motor abilities. 
We observed an improvement on the PRS scale after treatment; nevertheless, the beneficial effect was not sustained until the end of the study. The scale subitems gait pattern and ankle position, which are the two elements that are most closely related to spasticity of the gastrocnemii and soleus, improved significantly with BoNT/A. Gait speed, the item with the greatest functional value on the scale, also improved significantly, but this improvement was not sustained until the sixth month of followup. We also found that only one patient was able to ambulate without support, while the other 16 still needed support during the gait tests. These data, which show that functional gains were not sustained, support other authors' concern to lay greater emphasis on instruments to measure function when analyzing the applicability of BoNT/A A $^{10,18,22}$.

However, the objective of this study was to assess the efficacy of BoNT/A applied in a single session. Serial injections of BoNT/A may lead to a greater reduction in focal spasticity and allow children with CP to learn movement patterns that more closely resemble normal ones and to improve their balance and gait speed as well as increase step size when ambulating ${ }^{11}$. Hawamdeh et al. ${ }^{10}$ showed that there was an overall improvement for 18 months after three applications of BoNT/A in children with spastic diplegia. The improvement was greater than that observed when physiotherapy and orthoses were used in isolation and was sustained until the last follow-up session at 18 months. This suggests that BoNT/A may influence physiotherapy, prolonging and amplifying its effects and increasing the functional capacity of children with spastic diplegia.

In addition to increased functional capacity, another important benefit of long-term treatment with BoNT/A is that surgical interventions can be postponed ${ }^{6}$. Without treatment, muscles that have been spastic for a long time can develop fixed contractures that often require surgical procedures. Equinus recurs after corrective procedures are performed in early childhood. Reduced spasticity following BoNT/A applications can delay the need for surgery, thus reducing the possibility of deformities recurring ${ }^{11,17}$.

With regard to the effectiveness of BoNT/A, quantitative variables have been found to be predictive factors for a favorable treatment outcome. In terms of age, children under 48 months can show better results ${ }^{13}$. We assessed children from 2 to 11 years of age $(4.73 \pm 2.18$ years), and our initial results were significant. With younger children we might have been able to maintain the functional gains because the motor pattern of very young children provides greater scope for better development and recovery (a younger child has greater potential than an older child for increasing the plasticity of the central nervous system) ${ }^{13}$. Papadonikolakis et al. ${ }^{24}$, however, support the view that carefully selected patients can show an improvement following treatment with BoNT/A despite being older (average age 11 years). These authors used selection criteria that were similar to those we used, i.e., only patients who were undergoing physiotherapy, did not have fixed contractures and were able to ambulate were included in the study.

Fattal-Valevski et al. ${ }^{25}$ found that greater spasticity, an inability to ambulate and lower motor function levels are predictive factors for a good response to BoNT/A. In contrast with these authors' findings, in our study we observed that patients with a high degree of motor limitation were precisely those who had the worst response to BoNT/A treatment. Kay et al. ${ }^{26}$ followed up 23 children over the age of four years with more severe $\mathrm{CP}$ (including patients with quadriplegia) who had dystonic movements and fixed contractures in the ankle. The authors did not observe any differences between lower-limb spasticity in the group that received BoNT/A and that in the group that had been treated with physical therapy alone. Two possible explanations for Fattal-Valevski et al..$^{25}$ findings are that BoNT/A was injected in a larger number of motor points in patients with more severe $\mathrm{CP}$ or that small changes in function, tonus and the range of motion of joints can be detected more easily in these children.

Another interesting point, which we did not address in our study, is the influence of cognitive level and visual function. The role of cognitive and sensory development in the acquisition of motor abilities is well understood. Fazzi et al. ${ }^{13}$ showed that the best results in terms of gait improvement were produced by children with normal or borderline cognitive levels. Similarly, a significant improvement in gait was observed in patients with normal or borderline visual acuity.

As the predictive factors are well understood, BoNT/A treatment should be tailored to suit each patient. In addition, the effect and duration of treatment depends on the ability to deliver toxin to the target muscle(s); preinjection muscle physiology, including power, endurance and spasticity; connective tissue extensibility; and the range of motion of the joint".

A critical assessment of the predictive factors for a good therapeutic result, the physiopathology of spasticity, the mechanism of action of BoNT/A and an understanding that a child's organism is undergoing constant change are directly related to the key elements for effective therapy using BoNT/A, namely, suitably chosen patients; clearly defined treatment objectives as a result of discussion with the patient and his/her family; and an effective long-term strategy for managing the changes that take place in a child with CP who is in a growth and development phase $\mathrm{e}^{21,22}$. 
Family members must have realistic expectations about the BoNT/A treatment before the procedure starts. Bjornson et al. ${ }^{22}$ showed that the family members' expectations for the therapy were far removed from the actual effects of the treatment and that they had difficulty appreciating the benefits of the treatment.

On the other hand, patients and family members understand and rarely complain about the adverse effects of the treatment. BoNT/A is generally well tolerated and safe when used to treat spastic $\mathrm{CP}$ and rarely produces severe side effects. In agreement with the literature, no important side effects were observed in our patients. However, we did observe weakness in the lower limbs and falls probably related to a reduction in muscle tonus after the treatment - in individuals used to ambulating with spastic muscles ${ }^{11,15,17,24}$.

Although we did not use sedatives or local anesthetics, there were no complaints of pain at the injection site or local adverse effects because of traumatism as a result of sudden movements by the children. Koman et al. ${ }^{6}$ also failed to find adverse effects and reported that all their patients agreed to second injection sessions. Topical anesthetics are not effective in reducing pain produced by the injections because they do not affect the muscle underneath the skin at the injection site ${ }^{6}$. The argument for using general anesthesia when injecting BoNT/A is that it helps avoid emotional stress and anxiety in the child, especially when the procedure needs to be repeated in the future ${ }^{27}$. The use of sedatives such as oral midazolam, which causes amnesia, can be a safer, less expensive alternative to general anesthesia when the aim is to sedate the patient before the procedure ${ }^{15,27}$.

In the group of patients with spastic diplegia in the present study, a single session of injections of BoNT/A was safe and effective. There was an important, sustained change in the motor structure in the lower limbs of the children tested; however, functional changes were only observed when the effect of the medication was at its peak. These findings indicate that serial injections of the medication are required if all the positive effects obtained are to be maintained.

ACKNOWLEDGMENTS - The authors would like to thank Allergan, Inc.; which provided the botulinum toxin (Botox ${ }^{\circledR}$ ) for this study. Disclosure: The authors have nothing to disclose

\section{REFERENCES}

1. Nelson KB, Ellenberg JH. Epidemiology of cerebral palsy. Adv Neurol 1978;19:421-435.

2. Hagberg B, Hagberg G, Olow I. Gains and hazards of intensive neonatal care: an analysis from Swedish Cerebral palsy epidemiology Dev Med Child Neurol 1982;24:13-19.

3. Hagberg B, Hagberg G, Beckung E, Uvebrant P. Changing panorama of cerebral palsy in Sweden. VIII. Prevalence and origin in the birth year period 1991-94. Acta Paediatr 2001;90:271-277.
4. Koman LA, Smith BP, Shilt JS. Cerebral palsy. Lancet 2004;363: 1619-1631.

5. Hazneci B, Tan AK, Guncikan MN, Dincer K, Kalyon TA. Comparison of the efficacies of botulinum toxin A and Johnstone pressure splints against hip adductor spasticity among patients with cerebral palsy: a randomized trial. Mil Med 2006;171:653-656

6. Koman LA, Mooney JF 3rd, Smith BP, Walker F, Leon JM. Botulinum toxin type A neuromuscular blockade in the treatment of lower extremity spasticity in cerebral palsy: a randomized, double-blind, placebocontrolled trial. BOTOX Study Group. J Pediatr Orthop 2000;20:108-115.

7. Bohannon RW, Smith MB. Interrater reliability of a modified Ashworth scale of muscle spasticity. Phys Ther 1987;67:206-207.

8. Koman LA, Mooney JF 3rd, Smith BP, Goodman A, Mulvaney T. Management of spasticity in cerebral palsy with botulinum-A toxin: report of a preliminary, randomized, double-blind trial. J Pediatr Orthop 1994;14:299-303.

9. Russman BS, Tilton A, Gormley ME Jr. Cerebral palsy: a rational approach to a treatment protocol, and the role of botulinum toxin in treatment. Muscle Nerve 1997;6(Suppl):S181-S193.

10. Hawamdeh ZM, Ibrahim AI, Al-Qudah AA. Long-term effect of botulinum toxin (A) in the management of calf spasticity in children with diplegic cerebral palsy. Eura Medicophys 2007;43:311-318.

11. Koman LA, Brashear A, Rosenfeld S, et al. Botulinum toxin type a neuromuscular blockade in the treatment of equinus foot deformity in cerebral palsy: a multicenter, open-label clinical trial. Pediatrics 2001;108:1062-1071.

12. Hesse S, Brandl-Hesse B, Seidel U, Doll B, Gregoric M. Lower limb muscle activity in ambulatory children with cerebral palsy before and after the treatment with Botulinum toxin A. Restor Neurol Neurosci 2000;17:1-8.

13. Fazzi E, Maraucci I, Torrielli S, Motta F, Lanzi G. Factors predicting the efficacy of botulinum toxin-A treatment of the lower limb in children with cerebral palsy. J Child Neurol 2005;20:661-666.

14. Detrembleur C, Lejeune TM, Renders A, Van Den Bergh PY. Botulinum toxin and short-term electrical stimulation in the treatment of equinus in cerebral palsy.Mov Disord 2002;17:162-169.

15. Ubhi T, Bhakta BB, Ives HL, Allgar V, Roussounis SH. Randomised double blind placebo controlled trial of the effect of botulinum toxin on walking in cerebral palsy. Arch Dis Child 2000;83:481-487.

16. Teive HA, Zonta M, Kumagai Y. Tratamento da espasticidade: uma atualização. Arq Neuropsiquiatr 1998;56:852-858.

17. Molenaers G, Desloovere K, Fabry G, De Cock P. The effects of quantitative gait assessment and botulinum toxin a on musculoskeletal surgery in children with cerebral palsy. J Bone Joint Surg Am 2006;88:161-170.

18. Desloovere K, Molenaers G, Jonkers I, et al. A randomized study of combined botulinum toxin type A and casting in the ambulant child with cerebral palsy using objective outcome measures. Eur J Neurol 2001;(Suppl 5):S75-S87.

19. Eames NW, Baker R, Hill N, Graham K, Taylor T, Cosgrove A. The effect of botulinum toxin A on gastrocnemius length: magnitude and duration of response. Dev Med Child Neurol 1999;41:226-232

20. Slawek J, Klimont L. Functional improvement in cerebral palsy patients treated with botulinum toxin A injections: preliminary results. Eur J Neurol 2003;10:313-317.

21. El O, Peker O, Kosay C, Iyilikci L, Bozan O, Berk H. Botulinum toxin A injection for spasticity in diplegic-type cerebral palsy. J Child Neurol 2006;21:1009-1012.

22. Bjornson K, Hays R, Graubert C, et al. Botulinum toxin for spasticity in children with cerebral palsy: a comprehensive evaluation. Pediatrics 2007:120:49-58

23. Reddihough DS, King JA, Coleman GJ, et al.. Functional outcome of botulinum toxin A injections to the lower limbs in cerebral palsy. Dev Med Child Neurol 2002;44:820-827.

24. Papadonikolakis AS, Vekris MD, Korompilias AV, Kostas JP, Ristanis $\mathrm{SE}$, Soucacos PN. Botulinum A toxin for treatment of lower limb spasticity in cerebral palsy: gait analysis in 49 patients. Acta Orthop Scand 2003;74:749-755

25. Fattal-Valevski A, Giladi N, Domanievitz D, et al. Parameters for predicting favorable responses to botulinum toxin in children with cerebral palsy. J Child Neurol 2002;17:272-277

26. Kay RM, Rethlefsen SA, Fern-Buneo A, Wren TA, Skaggs DL. Botulinum toxin as an adjunct to serial casting treatment in children with cerebral palsy. J Bone Joint Surg Am 2004;86:2377-2384.

27. Bakheit AM. Botulinum toxin in the management of childhood muscle spasticity: comparison of clinical practice of 17 treatment centres. Eur J Neurol 2003;10:415-419. 